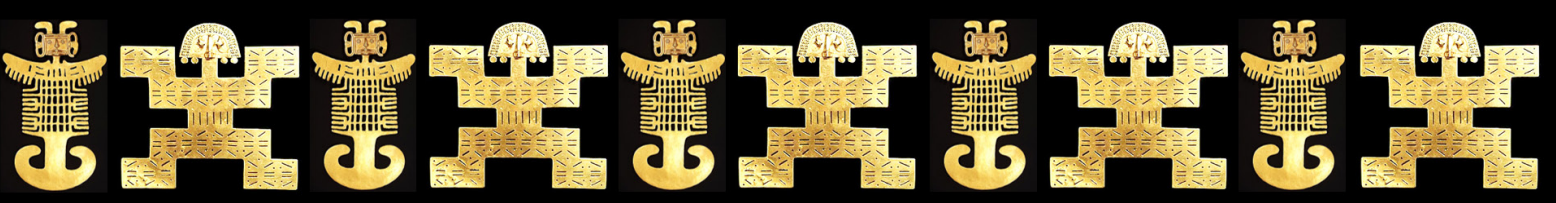

Artículo de reflexión E17A01. * Universidad de Antioquia.

Recibido 13.03.2020. * Aceptado versión final: 28.05.2020.

JEL: M12, L81, Z1. Pp. 149-164 * doi: 10.33571/teuken.v11n17a8

\title{
La lógica del Management y la experiencia sensible. Mandos medios y personal subalterno en un centro de distribución.
}

\section{Management logic and sensitive experience.}

Middle managers and junior staff in a distribution center.

\section{Héctor L. Bermúdez \\ COLOMBIA}

Dedicado a Fernando Cruz Kronfly, que me alienta al criticarme.

Resumen: Más que una simple ideología, el management es una racionalidad pues ha sobrepasado la esfera de la dirección del trabajo y se ha convertido en una mentalidad. Se mostrarán algunos ejemplos en los cuales se observa que la lógica managerial aparece encarnada en los mandos medios y que cuando reproducen con total convicción y coherencia sus retóricas, obtienen grandes dosis de satisfacción. El sufrimiento de ellos, es causado por el fenómeno opuesto: la incapacidad de obedecer sus premisas gracias a las exigencias que la lógica del management les impone. El personal subalterno, por su parte entiende tal racionalidad como una fatalidad $y$, sin mucho darse cuenta, la reproduce con resignación y, para protegerse de las exigencias que le impone, se contenta creyendo que puede "escapársele" diariamente, cuando su jornada termina.

Palabras clave: centro de distribución; experiencia sensible; management; mandos medios y personal subalterno.

Abstract: More than a simple ideology, Management is a rationality since have overpassed the sphere of the direction of the work and have converted in a mentality. It will be displayed some examples in which is possible to notice that the managerial logic appears embodied in the middle management and when be reproduced with total conviction its rhetoric, they get big dosses of satisfaction. Suffering of these people, is caused by the opposite phenomenon: the disability to obey the mentioned their premises thanks to the requirements that the logic of the management impose to them. The subordinate personnel, by their way understand that rationality like a fatality and by these, without realizing it, reproduce it with resignation, and to protect their selves from the requirements that are imposed to them, been happy knowing that can "escape" daily when their working day ends.

Keywords: distribution center; sensitive experience; management; middle management; subordinate personnel.

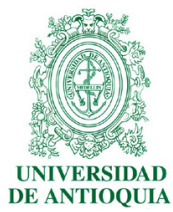

Héctor L. Bermúdez es Sociólogo de la Universidad Autónoma Latinoamericana, Magíster en Ciencias de la Administración de la Universidad Eafit y candidato a doctor en Sociología (PhD) de la Université du Québec à Montréal (UQÀM). Actualmente es Profesor Investigador en el Grupo de Investigación Comportamiento Humano Organizacional (COMPHOR) del Departamento de Ciencias Administrativas, Facultad de Ciencias Económicas de la Universidad de Antioquia, en Medellín, Colombia. 


\section{Lógica de gerenciamento e experiência sensível.}

Gerentes intermediários e funcionários juniores em um centro de distribuição.

Resumo: Mais do que apenas uma ideologia, a administração é uma racionalidade porque foi além da esfera da direção do trabalho e se tornou uma mentalidade. Alguns exemplos serão mostrados nos quais se observa que a lógica gerencial aparece incorporada na gerência intermediária e que, quando ela reproduz sua retórica com total convicção e coerência, obtém grandes doses de satisfação. O sofrimento é causado pelo fenômeno oposto: a incapacidade de obedecer a suas premissas, graças às exigências que a lógica gerencial impõe. Os funcionários juniores, por sua vez, entendem essa racionalidade como uma fatalidade e, sem perceber, a reproduzem com resignação e, para se protegerem das exigências impostas, contentam-se em acreditar que podem "escapar" diariamente, quando termina o dia.

Palavras-chave: centro de distribuição; experiência sensível; management; gerência intermediária; pessoal subordinado

\section{La Lógica Managerial ${ }^{1}$}

The fundamental principles of scientific management are applicable to all kinds of human activities, from our simplest individual acts to the work of our great corporations. ${ }^{2}$

Frederick W. Taylor, 1919: 7

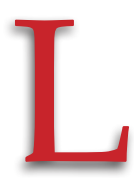

a "revolución managerial"3 es una de esas raras revoluciones en la historia, en la que tanto los dominantes como los dominados participan activamente, y en el mismo sentido -aunque casi siempre sin saberlo-, en la búsqueda de la transformación de las estructuras sociales, económicas y políticas. En ocasiones, la contribución de los asalariados ha sido, más que voluntaria, deseada (Gori, 2009; Gori et Del Volgo, 2009; Lordon, 2010). Como se verá, la ideología managerial juega un papel fundamental en la participación de los dominados, entre

\footnotetext{
${ }^{1}$ Algunas (pocas) ideas de este apartado aparecieron publicadas en Bermúdez (2019: 272-273).

${ }^{2}$ Traducción libre: Los principios fundamentales del management científico son aplicables a todo tipo de actividades humanas, desde nuestros más simples actos individuales hasta el trabajo de nuestras grandes corporaciones (énfasis añadido).

${ }^{3}$ Diferentes enfoques aceptan el concepto de "revolución managerial" (Burnham, 1942; Boltanski y Chiapello, 2002; Linhart, 2013; de Gaulejac, 2005). Algunos autores se refieren a este fenómeno como "managerialización" de la sociedad, es decir "la importación a la esfera política de maneras de hacer, salidas del mundo de los negocios" (Saint-Martin, 2009, p.24; cf. también Rothmayr, 2013). Nótese, sin embargo, que estos términos son correctos, tanto en el mundo anglófono (eg.
} 
otros aspectos gracias a las retóricas que le son inherentes. Se trata de una revolución que, como la mayoría de ellas, se caracteriza por un enorme nivel de violencia. Sin embargo, esta se diferencia de las demás porque tal violencia es a menudo sutil, pues, aunque ciertamente puede destruir la salud física -el cuerpo, el organismo-, causa sobre todo un gran sufrimiento emocional y se manifiesta fundamentalmente en la salud mental de los dominados (De Gaulejac, 2011a; Enriquez, 2005; Dejours, 1998). La violencia que ejerce es institucional; es decir que está determinada por una lógica abstracta que aparece como instituida, lo que hace que muchas veces sea interpretada por el actor social como una fatalidad ante la cual resulta inútil resistirse (Kaës, et al., 1998). Antes de examinar cómo esta lógica managerial ha sido interiorizada en los mandos medios actuales, será necesario precisar algunos términos.

Ya en los albores de la década de 1950, Hannah Arendt (1972) se inquietaba por la presunción del carácter científico de las ideologías. Según la autora, "éstas combinan el enfoque científico y los resultados de orden filosófico pretendiendo constituir una filosofía científica":

Lapalabra "ideología" parece implicarque una idea puede volverse el objeto de una ciencia de la misma manera que los animales son el objeto de la zoología, y que el sufijo logia en ideología, como en zoología, no indica más que las logoi, las declaraciones científicas sobre el tema. Si esto fuera cierto, una ideología sería, desde luego, una pseudociencia y una pseudofilosofía, transgrediendo al mismo tiempo las limitaciones de la ciencia y las limitaciones de la filosofía (Arendt, 1972, p. 216). ${ }^{4}$

Es en este sentido exactamente que aquí se utiliza el término "ideología managerial". Con esta expresión se denomina al halo científico y filosófico que acompaña al discurso del management. Es de esta manera que éste se ha blindado desde sus orígenes hace un siglo y es así que se desarrolla y se actualiza: mostrándose, desde el punto de vista filosófico, como

Burnham, 1942; Rourke \& Brooks, 1964; Jiambalvo, 2020; Silverstein, 2020), como en el francófono (eg., Pagès et al., 2019; Rappin, 2019; Soulié, 2018). No obstante, el término "managerial" es un barbarismo que está lejos de ser aceptado por la RAE. A pesar de esto, algunos sinónimos como "gerencial" o "administrativo", etc., se asocian simplemente a la dirección de empresas, mientras que "managerial" proviene directamente del término "management" el cual se refiere no sólo a lo administrativo, sino a aquella racionalidad que influenció a sectores tan variados como la educación (primaria, secundaria, universitaria), el gobierno, el sector público, la política y la economía internacionales.

${ }^{4}$ Traducción libre. 
una lógica y desde el punto de vista científico, como regido por leyes. ${ }^{5}$ El management paulatinamente se convirtió en un instrumento de explicación y de acción. Así, todos los jefes deberán pensar de manera lógica (ser calculadores) y aplicar los principios científicos con espíritu pragmático (ser prácticos). En este mismo sentido, es fácil estar de acuerdo con François Rastier cuando indica que la ideología managerial es "una concepción general del universo social con objetivos exclusivamente económicos, basados en obtener máximas ganancias en el corto plazo y cuyos métodos -los administrativos- calcados de los que utilizan las grandes empresas, son empleados a la manera coercitiva de eso que se llama el soft power" (Rastier, 2013, p.11). Este anglicismo, utilizado en el campo de las relaciones internacionales, fue acuñado por Joseph Nye hace ya tres décadas (cf. Nye, 1990). Según este autor, a diferencia del hard power, que "se basa en la coacción y se deriva del poderío económico y militar", el soft power, "es la capacidad de conseguir lo que uno quiere atrayendo a otros, en lugar de amenazándoles o pagándoles. Está basado en la cultura, los ideales y las medidas políticas" (Nye, 2004).

Presentaremos más adelante, algunos ejemplos en los que se evidencia lo innecesario de la coacción en la lógica del management, la cual, al contrario, ensaya a convencer a todos de que no hay alternativa que seguir sus preceptos. Recuérdese, en el contexto de la política económica internacional -en los albores del neoliberalismo-, el estribillo de Margaret Thatcher para imponer su visión unificada del mundo: There is no alternative (TINA). Creemos -de nuevo con Rastier (2013, p.22-23)-, que una ideología "para mantener la coherencia de sus tesis, debe no solamente naturalizarlas, presentarlas como un reflejo indiscutible de la naturaleza de las cosas, sino incluso hacer desaparecer todas las realidades que no cuadran con sus intereses. De ahí la necesidad de las frases de cajón y la importancia de organizar la negación de todo aquello de lo que ésta no puede hablar". Por eso, para hacerse seguir, el management utiliza sus retóricas, pues una ideología "se concreta en discursos, géneros y estilos; mejor dicho, se expresa en formas lingüísticas y semióticas" (Rastier, 2013, p.88). Así, consideramos que el lenguaje managerial funciona "como un inventario de señales, y como todos los discursos de cajón, éste no sirve sino para medir la docilidad, incluso el servilismo de aquellos que lo emplean" (Rastier, 2013: p.89).

\footnotetext{
${ }^{5}$ Decimos "hace un siglo" puesto que, aunque la dirección de empresas es antigua, nos referimos al management desde que fue fundado con pretensiones científicas (eg., Taylor, 1911, 1919; Fayol, 1917) y se comenzaron a fundar programas universitarios en este campo (cf., Rumelt, Schendel \& Teece, 1994).
} 
Sin embargo, habrá que hacer varias advertencias. En primer lugar, la categoría "ideología" ha sufrido un cierto desgaste epistemológico, pues el término ha sido de uso corriente en el lenguaje de opinión y en el de las masas, lo que obliga a utilizarlo con precaución. Por "desgaste epistemológico" habrá que entender aquí la decadencia de ciertos conceptos para contribuir a realizar explicaciones concretas. Esto, generalmente debido al abuso de ciertos términos sin advertir sobre su polisemia, su evolución o desarrollo como operadores explicativos, etc., lo cual puede terminar convirtiéndolos en conceptos vagos en lugar de categorías empíricas útiles. Una ideología es pues, mucho más que un "simple discurso moralizador que tendería a ocultar los intereses materiales que a menudo son puestos en evidencia en las prácticas", según la advertencia de Boltanski y Chiapello (2002, p.33).

Además, con el management no estamos siempre ante "la coerción brutal que opera ordinariamente" ni ante "la adhesión consciente a un sistema de representaciones más o menos ilusorias" (Delmas, 2010). Es mucho más que esto, pues en realidad, consideramos que el management opera como "un sistema de normas inherente a un discurso, encarnado en las instituciones, puesto en ejecución en las técnicas, los procedimientos y los dispositivos que orientan las prácticas". Es decir, "como un entramado en el cual los individos tienen que actuar, sin incluso tener que reflexionar sobre los principios, las causas y los efectos de sus prácticas", según la definición de racionalidad que brindan Pierre Dardot y Christian Laval (2010).

Para decirlo utilizando ciertas ideas weberianas: esta racionalidad managerial ha creado una nueva relación moral entre los seres humanos y su trabajo cotidiano; como se verá en los ejemplos siguientes, unas nuevas formas de socialización han sido inventadas con el management, y éstas se están perfeccionando con el tiempo.

\section{Algunos ejemplos concretos}

Los ejemplos que se presentan a continuación emanan de una investigación que se llevó a cabo en un centro de distribución de una cadena canadiense líder en la comercialización al detal de productos alimenticios. El trabajo de terreno incluyó dos pasos metodológicos. Una observación participante de un cuatrimestre de duración en la cual el investigador trabajó como preparador de pedidos y un conjunto de entrevistas cualitativas poco dirigidas, hechas a los directivos y a los mandos medios. 


\section{La ilusión del jefe de dominar la cólera del subalterno}

Uno de los aspectos de la ideología managerial que pudo observarse está relacionada con los desafíos de los jefes para ensayar a controlar la oposición de sus trabajadores, su cólera, su falta de obediencia. El ejemplo de uno de los dirigentes del centro de distribución muestra claramente su afán socializador. Cuando se le interrogó al respecto de sus más grandes satisfacciones desde el punto de vista "subjetivo" en el trabajo cotidiano -es decir, al margen de sus satisfacciones "objetivas" como el alcance de los indicadores de gestión, el cumplimiento de presupuestos y metas, etc.-, este respondió sin mucho pensar que era el hecho de dominar la rabia de sus trabajadores y pone el ejemplo de uno de ellos que se jubilaría próximamente:

Hay un empleado que se pensionará este próximo 15 de julio. La primera vez que yo establecí contacto con él, hace un par de años, estaba furioso. Nunca nos habíamos visto, no nos conocíamos. Fue en una reunión informativa. Yo me presenté como el nuevo jefe y la primera cosa que me dijo fue: "iQué va, usted es igual que los otros!" Entonces yo le contesté: "¿Por qué estás de tan mal humor? A lo que me replicó: "Yo trabajo actualmente sólo para esperar mi pensión. Inmediatamente lo consiga, me largo... de una: me voy $\mathrm{pa}^{\prime}$ la mierda" ... Figúrese usted que me lo encontré esta semana, el miércoles, en la reunión informativa del mes y él estaba saludando de mano a todo el mundo. Había cambiado: jestaba de buen humor! A mí mismo me dio la mano delante de todo el mundo. Yo le deseé una buena jubilación... todo el mundo nos veía, nos escuchaba... Eso sí que causa satisfacción. Yo le dije: "ha sido un placer trabajar contigo", y él respondió: "el placer ha sido mío". ¡Qué alegría: yo conseguí dominar su resentimiento!

Varias observaciones son necesarias. La primera, que es exclusivamente de sentido común (no hay que formular un proyecto de investigación para detectarlo), es que un trabajador que se despide de sus compañeros porque desde hace varios años espera su jubilación tiene todo para estar contento, sobre todo si se trata de un trabajo arduo, de obrero en una bodega de frutas, verduras y derivados lácteos que opera a temperaturas que nunca superan los $13^{\circ} \mathrm{C}$. De hecho, habría que examinar con atención la amabilidad con la que el trabajador se despide del director: no se cuenta aquí con suficientes datos para saber si se trata de ironía -lo cual bien podría ser el caso-, o frases de cajón, simplemente porque ya no trabajará bajo sus órdenes, etc. Sin embargo, una segunda observación, esta sí constatada por el análisis de los testimonios conseguidos durante la investigación, tiene que ver con que, a pesar de lo que se viene de señalar, el interés del director de "dominar la cólera" de sus trabajadores es totalmente sincera. Sus argumentos son verídicos y, ciertamente, es una fuente de satisfacción aquello de conseguir que sus trabajadores no 
le manifiesten descontento y oposición. Él mismo lo demuestra cuando se le interroga, en el mismo contexto, pero por los aspectos subjetivos que le causan la mayor tensión:

Bueno, de la otra parte, del lado negro; digamos del estrés, de la angustia ... Hay una cosa que yo aseguro (desde luego nunca en las reuniones, sino con mis supervisores, etc.), es que el $80 \%$ de nuestra energía es por causa del $20 \%$ de nuestros empleados. Uno gasta el $80 \%$ de la energía en ese $20 \%$ de empleados difíciles. Aquellos con los que uno no es capaz. Con los que uno no logra hacerlos evolucionar, hacer que trabajen correctamente. Esos que quieren siempre explotar el sistema. Eso causa mucho estrés. El estrés de corto plazo.

Nótese de nuevo que este directivo encarna la ideología del management actual y reproduce sus retóricas. Aplicar porcentajes y datos estadísticos a lo referente a la dirección del personal aumenta su autoestima y mejora su autoconfianza. Pero, científicamente hablando, tales datos-expresados en el célebre principio de Pareto (de los 80-20)-, no tienen, en este contexto, ningún valor estadístico; simplemente, para decirlo en términos orwellianos, forman parte de la neolengua del management (cf. Orwell, 1977). El directivo la utiliza (sin saberlo) para legitimar una idea sobre el valor de este ejercicio de dirigir al personal que no obedece. La etiqueta de "empleados difíciles" es la prueba: no es que el trabajador sea difícil. Simplemente, es que algunos expresan, de manera más abierta que otros, su disgusto y su oposición. Lo que resulta realmente difícil es que la ilusión del director se materialice; es decir, que se haga realidad la utopía de conseguir que todos los subalternos obedezcan de manera no problemática, o por lo menos, que retengan su rabia, que no la expresen abiertamente.

Además de la satisfacción que causa en el jefe creer que lleva a cabo ejercicios de adoctrinamiento exitoso, pudo notarse que hay también unos encuentros disciplinarios que operan en este mismo sentido del afán de socializar al trabajador. Cuando, pasadas las primeras ocho semanas, un nuevo trabajador no alcanza el 95\% de productividad, es convocado a una reunión disciplinaria a la que asisten, además del trabajador en cuestión, el superintendente de turno y un representante sindical. En estas reuniones, reina la tensión. El trabajador sabe que su permanencia en la empresa está en peligro; además, los mandos medios coinciden, sin excepción -directores, supervisores, contramaestres- en que esta es la tarea más penosa entre todas las que les corresponde realizar. Son sin embargo reuniones bastante cordiales. Pudo constatarse que son dirigidas con un gran nivel de profesionalismo por los mandos medios que se encargan de ellas ${ }^{6}$. 
Según las propias palabras del superintendente, "la empresa ensaya a conservar los trabajadores que seleccionó y que formó". La dirección considera que ha invertido grandes esfuerzos para reclutar y entrenar a un nuevo trabajador y que por tal razón tiene como"filosofía" indicarle si su rendimiento no es el bueno y que por tal razón su período de prueba está en peligro:

No tiene mucho sentido que un nuevo trabajador pierda su puesto sin conocer las razones. Nosotros estamos convencidos de que vale la pena indicarle sus puntos débiles y buscar la manera de que pueda mejorar. Y esto para conservar al trabajador. Es un acuerdo gana-gana. No se trata de que los nuevos trabajadores rivalicen entre ellos para saber cuál es el mejor y cuál el peor. Se trata más bien de asegurarnos, en calidad de jefes, que los trabajadores que son reclutados y que tienen dificultades a alcanzar su productividad indiquen, ellos mismos, aquello que ellos consideran que se puede hacer para establecer un compromiso entre la empresa y ellos con el fin de garantizar que la productividad alcanzada sea respetada.

En el discurso del superintendente, se aprecia con claridad la profunda convicción de que actúa correctamente. Pudo comprobarse que este tipo de mandos medios realmente se interesa en conservar a los empleados "reclutados". Sin embargo, no disponen siempre de los elementos críticos necesarios para detectar, por una parte, que ellos utilizan los eufemismos propios a la neolengua managerial y, por otra, que son incoherentes en lo que concierne a su interpretación de la competencia entre los trabajadores, pues el software puede, efectivamente, poner a los preparadores a competir entre ellos, a luchar de manera individual por indicadores precisos. Conviene notar sin embargo que, en realidad no siempre se trata de una competición entre los preparadores por "ser el mejor" (el que consigue el mejor indicador de productividad que todos), porque entre ellos acuerdan -incluyendo un poderoso ejercicio de autorrestricción-, un rendimiento del $95 \%$, y se esfuerzan por nunca alcanzar el $100 \%$ o más. La competencia tiene que ver más bien con que cada uno sabe el porcentaje

\footnotetext{
${ }^{6}$ El investigador mismo fue convocado a una de estas reuniones disciplinarias, puesto que, al cabo de sus primeras ocho semanas de trabajo como preparador de pedidos que realizaba durante su observación participante, tenía un porcentaje inferior al 95\% exigido por los estándares de medida de productividad del centro de distribución. Se advierte que la reunión disciplinaria no fue grabada porque tuvo lugar en un horario en el cual el investigador estaba en curso de efectuar su trabajo de preparador de pedidos. Las citas largas textuales fueron tomadas en las entrevistas poco dirigidas hechas al personal de mandos medios, las cuales sífueron registradas en su totalidad y transcritas para su análisis.
} 
que deberá alcanzar él mismo, independientemente de que sus colegas alcancen el indicador que el software les asignó.

En cuanto a la neolengua, se ve claramente la influencia de la retórica managerial que impulsa a los trabajadores al empoderamiento y la autoresponsabilidad [empowerment]. Se quiere llamar la atención sobre un axioma harto problemático para las dinámicas tranquilizadoras de los asalariados subalternos. Si la historia termina mal, si el trabajador es despedido, no será culpa de la empresa o sus directivos, pues ellos hicieron los esfuerzos necesarios para demostrarle al trabajador que les interesaba conservarlo. Así, este último asume que, en el eventual caso en que fuere despedido, él mismo sería el responsable y nadie más. El trabajador interpretará entonces que el único culpable es él mismo; que el incompetente es él, pues no estuvo a la altura de las exigencias del puesto. Su desencanto, su rabia y su frustración no hallarán un agente externo sobre el cual proyectarse y las dirigirá contra él mismo, pudiendo degenerar en un ejercicio de masoquismo y autodestrucción que, además de ser una fuente potencial de sufrimiento, puede alimentar angustias profundas y causar graves daños a la salud mental y física (cf. de Gaulejac, 2011a).

Esto no quiere decir que el "culpable" sea el superintendente. Nótese que se trata más de la potencia de una ideología. Tanto para el superintendente, como para el subalterno, "la empresa" ofreció las oportunidades de formación y de retroalimentación para que este último realice el proceso de trabajo según lo que está estipulado por la organización. La decisión de despedir (o de conservar) es entonces una decisión lógica.

Por otra parte, lo que se pudo observar -al menos en el curso de esta reunión específica-, es que el representante sindical se limita a escuchar, él no participa en la defensa del nuevo trabajador y parte de la premisa de que la empresa tiene la razón. Es decir que ésta se basa en datos objetivos: la cifra de productividad (el porcentaje obtenido por el preparador) es inferior a lo que está establecido por el software que mide el rendimiento establecido. El representante sindical se rinde ante la evidencia de la información proveniente del software y no encuentra nada qué argumentar. Al finalizar la reunión, simplemente firma un documento en el cual se indica que él fue testigo del encuentro, eso es todo. En este sentido, su presencia opera más como una prueba de la que dispone la empresa en caso de un proceso legal si llegare a tomar la decisión de despedir al trabajador. La ideología managerial aparece interiorizada en cada uno de estos personajes sociales: en el responsable de los intereses de la dirección, en el representante de los intereses del trabajador subalterno y en el propio interesado, el ejecutante de la tarea. 


\section{El placer de la "libertad” vs. el sufrimiento de la obligación}

Se dicen muchas idioteces acerca de los sufrimientos de la clase trabajadora. Yo no siento tanta compasión por los obreros... El obrero sufre físicamente, pero cuando no está en el trabajo es un hombre libre. Al contrario, en cada una de estas cajitas de estuco vive un pobre desgraciado que no es nunca libre excepto cuando está a punto de dormirse y sueña que ha tirado a su jefe al fondo de un pozo y que lo está bombardeando a pedradas.

Las "cajitas de estuco" a las que se refiere George Bowling, el personaje de la novela de Orwell, son las casas de los empleados de oficina de Crozier (1965), los mismos célebres cuellos blancos de Mills (1966), los cuales nunca han parado de extender y extender sus horarios hasta el punto de que algunos de ellos, hoy por hoy, para protegerse, trabajan tan alienados que dicen sentirse orgullosos de ser "libres de trabajar 24 horas sobre 24" (de Gaulejac, 2011b, p.64). Al contrario de ellos, la sensación efectiva de libertad vivida por la mayoría de los asalariados de base, puede operar como un antídoto al sufrimiento en el trabajo cotidiano, a pesar de que éstos se ocupen de actividades muy penosas. En este sentido, Marco, un mejicano de unos cuarenta y cinco años, que emigró a Quebec hace ya veinte, expresa lo siguiente:

Yo trabajo aquí por mis hijos. Este trabajo es duro y esta bodega es una mierda. Los jefes son unos imbéciles. El trabajo de preparador de pedidos es el peor de todos. Yo ahora soy operador de montacargasy eso cambia mucholas cosas, incluso sies un trabajo que no me gusta. Pero tengo un buen salario. Lo único que tengo que hacer es respetar un horario y listo. Nunca estoy obligado a llevarme trabajo para la casa. Y durante ese horario, no tengo nada diferente que hacer a un cierto esfuerzo físico (que, insisto, disminuye mucho cuando uno pasa de preparador a operador exclusivamente a causa de años de servicio). Cuando mi horario termina, mis responsabilidades paran. Punto. Y cuando la paga llega, es más que suficiente para pagar la hipoteca, los estudios de mis hijos, la alimentación, etc. -y termina con una carcajada sincera-: y además jel dinerito me alcanza para mis botellitas de tequila, güey!

Este es solamente un ejemplo, pero los testimonios recolectados van todos en el mismo sentido. Ciertamente, cuando los preparadores de pedidos, los operadores de montacargas, los recibidores de mercancías,

\footnotetext{
${ }^{7}$ Traducción libre.
} 
etc., terminan su jornada de trabajo, son libres como los obreros que envidia míster Bowling. Pero, lo más interesante es que el mero hecho de saberlo les hace felices. Para serlo, no tienen que esperar el sonido de la campana como señal de autorización para cambiarse el uniforme e ir a registrar su salida con la tarjeta del reloj de control como, en efecto, sucede en esta empresa. Desde luego, según lo que se pudo constatar, cuando eso se produce -el campanazo que anuncia el fin del turno-, las expresiones de alegría y de excitación son tales que todo parece una regresión a los comportamientos eufóricos de los adolescentes en la secundaria. Los asalariados gritan, ríen, bromean, corren y hay toda una exaltación gestual y verbal manifiesta.

Sin embargo, no es sobre este tipo de episodios que se quiere aquí llamar la atención, porque, aunque se repiten todos los días y, sin duda, representan un aporte de placer, estos son efímeros. Es más bien sobre ese estado emocional que subyace toda la jornada sobre el que vale la pena detenerse a analizar. Incluso si la tarea es penosa -y entre más dura, más intensa es la sensación-, saber que se será libre cuando finalice el turno, alimenta la impresión de ser feliz durante toda la jornada.

Nótese la importancia de este tipo de paradojas. Durante el desarrollo del proceso de trabajo, es decir, mientras ejecuta la actividad cotidiana, el trabajador experimenta cierta alegría por anticipación, al pensar que después de terminar su jornada de trabajo, no tendrá que pensar más en su tarea. Él está dentro del trabajo, pero al proyectarse fuera de él, consigue equilibrarse. Una vez afuera, no tiene que pensar más en ninguna responsabilidad relacionada con su trabajo. Él sabe que irá a ver a sus hijos, o que tomará un par de cervezas con sus amigos. Él puede planificar sus descansos cada semana, su asistencia a un evento deportivo, o ir de pesca, o a la discoteca, etc. Su imaginación se desplaza hacia afuera, donde no hay jefe, donde no tiene que obedecer instrucciones y donde puede comportarse según el ritmo natural de su organismo. Y esto sucede todos los días, durante toda la jornada. En esto consiste la diferencia con el placer efímero cercano al sonido de la campana que anuncia la finalización del turno. El otro placer, aquel de la esperanza de estar siempre ad portas de la libertad, es un placer continuo, de largo aliento y compartido por todos los trabajadores de la base. Sin mucho racionalizarlo, por el simple hecho de saberlo, éstos se identifican de manera gregaria a este tipo de fenómenos. Así, aunque la tarea como tal no sea gratificante, el asalariado compensa el hecho de saberla ardua, con su proyección hacia la libertad exterior que él imagina diariamente que encontrará cuando su jornada de trabajo termine. 
Desde luego, es necesario evitar toda asociación directa entre el hecho de que cada vez que el trabajador termine su trabajo, él se va a divertir. Resulta apenas evidente que su vida "en el exterior" puede estar más o menos cargada de sufrimiento según su propia biografía, sus problemas personales, familiares, de salud, etc. De hecho, en ocasiones, puede demostrarse que, al contrario, él podría sentir que su trabajo "le ayuda" a combatir ciertas experiencias desagradables de su vida afectiva, familiar, etc. Es fundamental entonces contextualizar. Una cosa es que el sentimiento de libertad que aquí analizamos opere como una fuente potencial de placer y otra muy diferente $-y$ muy ingenua desde el punto de vista sociológico- es asegurar que el trabajador sufre en el trabajo y es feliz por fuera de él. Este tipo de análisis deberá ser dialéctico y no perder de vista que el universo del trabajo (así como el de la vida familiar, etc.) incluye tanto fuentes de sufrimiento como de placer.

En lo que concierne a los mandos medios, este fenómeno opera de manera contraria. Éstos gozan de menos libertad en este sentido. Realmente, la mayoría de ellos permanece gran parte del tiempo sujetada al trabajo, a la empresa, a la tarea, incluso después de haber terminado sus horas reglamentarias de trabajo.

Los estudios sociológicos de estas ambivalencias entre la vida del trabajo y la vida del hogar no son nuevos en absoluto. Enriquez (2006), recuerda que un autor como Weber ya se había consagrado a investigar ciertas explicaciones concernientes al doble rol que los trabajadores de oficina debían adoptar según estuvieran en el lugar de trabajo o con su familia:

Como Weber (1922) lo ha señalado, el individuo perteneciente a una empresa -pública o privada- debe comportarse como un funcionario; es decir, como un ser totalmente dedicado a su función, frío, objetivo, sin cambios de humor durante su tiempo de trabajo, dispuesto a volver a encontrar sus sentimientos humanos cuando sale de su organización, se encuentre con su familia o sus amigos y pueda expresar sus deseos reprimidos durante sus horas laborales (Enriquez, 2006, p.905).

Sin embargo, se quiere insistir en que, incluso si en muchos aspectos el comportamiento de los mandos medios contemporáneos en su trabajo es diferente de aquel que tienen con su familia, sus amigos, etc., las responsabilidades inherentes a sus puestos les persiguen donde ellos vayan y no pueden, como lo mostraba Weber hace ya un siglo, "volver a encontrar sus sentimientos humanos". En otras palabras, la dictadura de la racionalidad managerial les impide sustraerse de sus obligaciones, mientras que los asalariados de la base sí consiguen hacerlo. 
En realidad, es fácil constatar que entre más se asciende en el escalafón jerárquico, más se tiene que estar implicado en las responsabilidades del trabajo. Los mensajes electrónicos, los SMS (Short Message Service), las llamadas al celular, etc., pueden presentarse -y de hecho así pasa- 24 horas al día. Esto es bien claro en el ejemplo de este centro de distribución que funciona 24 horas sobre 24 ya que su operación-aprovisionaroportunamente la red de almacenes- no debe interrumpirse en ningún momento.

El testimonio de los jefes lo confirma. "Yo no puedo darme nunca el lujo de desconectarme, incluso en vacaciones, yo debo saber qué pasa", señala uno de los directivos entrevistados. Otro, indica con una especie de tono triunfalista sin ser consciente de la paradoja: "Normalmente, todo el tiempo anda uno en línea con el trabajo, a toda hora uno quiere mirar sus e-mails, incluso en la noche, etc., ipero, en vacaciones, ahí sí ... en vacaciones, yo me desconecto!"

Se pudo constatar igualmente que los superintendentes y los contramaestres - al igual que su jefe, el director que se acaba de mencionar-, sienten, ellos también, la necesidad de estar mirando todo el tiempo sus e-mails y sus SMS, incluso por fuera de las horas laborales: "en las madrugadas y en las noches de insomnio" confiesa uno de ellos. En realidad, ellos no pueden "desconectarse" porque, como personal directivo, están atrapados en una lógica que ejerce sobre ellos una extorsión: ellos sienten que vale más estar bien informados todo el tiempo, pues si no lo están, sus jefes, sus colegas (y ellos mismos) pensarían que están "ausentes", que no están al corriente de lo que pasa en su vida profesional cotidiana; están convencidos que pueden causar la impresión de una falta de compromiso con la empresa y con las responsabilidades por las cuales les pagan. Esto prueba que interiorizaron la racionalidad del management. Habrá que notar que el chantaje que nace de la ideología managerial se instala con potencia en el imaginario de los mandos medios y convierten sus premisas en axiomas. Es como si existiera un "perfil universal ideal" del dirigente (de todo nivel) que incluye la responsabilidad de estar "conectado" todo el tiempo para poder estar bien informado. Esto opera como un valor incuestionado de la axiología del management contemporáneo.

\section{Consideración final}

Eso que representa para los trabajadores de base una fuente potencial de placer -la ilusión de libertad cuando terminan su horario de trabajo-, puede significar para los mandos medios una fuente potencial de sufrimiento. Estos últimos sienten la decepción subyacente de no poderse "desconectar" ni durante el tiempo en que realizan sus funciones, ni por fuera de éste; ellos saben que todo el tiempo están "en línea" con 
el trabajo. Esto causa ciertos niveles de desequilibrio psicológico entre la representación que hacen de su tiempo de trabajo y su tiempo de descanso. Esto produce en algunos la impresión de que nunca descansan. Incluso en los tiempos de reposo completo, el tiempo para dedicar a la familia, al esparcimiento, etc., el fantasma de las responsabilidades les espanta. Y su desespero es enorme porque, víctimas de la ideología managerial, promueven ellos mismos, sin saberlo, la idea de que "la vida profesional es así". No sobra repetir la idea: no es que "debería ser" así. No estamos ante una deontología, no. Simplemente, es así. Esta naturalización de las responsabilidades profesionales de los mandos medios más allá del escenario de trabajo obedece a una "ontología" fuertemente difundida con el modelo entidad-relación hegemónico en las ciencias de la organización, aquél del positivismo lógico. Así lo indica, por ejemplo, Rastier (2013, p.110):

este movimiento de pensamiento propone una concepción lógica del mundo tal que el universo se resume a unas entidades objetivas (los individuos lógicos) y unas relaciones lógicamente definibles. En las representaciones lógicas, los términos aseguran la referencia a los objetos, y las proposiciones la adecuación a los estados de cosas (Sachverhalte)".

Nótese que, para los mandos medios, lo lógico es comportarse según lo dictan las premisas del management, resistirse a ellas es pues, ilógico; contradecirlas, absurdo. Por eso, reproducirlas es apenas obvio. Y gratificante. Y, para el personal subalterno, lo lógico es que sus jefes las obedezcan todo el tiempo, mientras que ellos creen -también todo el tiempo-, que pueden escapárseles cuando termine su jornada laboral. Estos últimos tampoco encuentran muchos motivos para resistirse a la racionalidad managerial...

... Ambas partes son pues, felices reproduciendo una lógica de dominación.

\section{Referencias bibliográficas}

1. Arendt, H. (1972). Les origines du totalitarisme. Le système totalitaire. París: Du Seuil.

2. Bermúdez, H. L. (2019). Los mandos medios de la organización del trabajo Voice Picking: ¿una lumpen-administración? En: G. Ramírez, J. A. Rosas y O. Lozano, Realidades organizacionales e institucionales de Méjico y Latinoamérica: Perspectivas de Análisis, Tomo 1: Dimensión subjetiva de las organizaciones (pp. 263-294). Ciudad de Méjico: Grupo Editorial HESS.

3. Boltanski, L. y Chiapello, E. (2002). El nuevo espíritu del capitalismo. (1a. ed., 1999). Tr. Esp. A. Riesco, M. Pérez, R. Sánchez. Madrid: Akal. 
4. Burnham, J. (1942). The Managerial Revolution or What is happening in the world now. London: Putnam and Company Ltd.

5. Crozier, M. (1965). Le monde des employés de bureau : París: Du Seuil.

6. Dardot, P. y Laval, C. (2010). La nouvelle raison du monde. Essai sur la société néolibérale. París: La Découverte.

7. Dejours, C. (1998). Souffrance en France. La banalisation de l'injustice sociale. París: Du Seuil.

8. Delmas, C. (2010). Pierre Dardot, Christian Laval, «La nouvelle raison du monde. Essai sur la société néolibérale », Lectures. Les comptes rendus. URL: http://journals. openedition.org/lectures/1194

9. Enriquez, E. (2005). Violence du pouvoir. La violence subtile dans l'entreprise. Sud/ Nord, 20 (1), 59-69. doi: 10.3917/sn.020.0059

10. Enriquez, E. (2006). L'institution de la vie mutilée. Revue française de psychanalyse, 70 (4), 899-917. doi: 10.3917/rfp.704.0899

11. Fayol, H. (1917). Administration industrielle et générale. Extrait du Bulletin de la Société de l'Industrie Minérale (3e livraison de 1916). París: H. Dunod et E. Pinat, Éditeurs.

12. Gaulejac, V. de (2005). La société malade de la gestion. Idéologie gestionnaire, pouvoir managérial et harcèlement social. París: Du Seuil.

13. Gaulejac, V. de (2011a). Travail, les raisons de la colère. París: Du Seuil.

14. Gaulejac, V. de (2011b). Management, les maux pour le dire. Projet, 323 (4), 61-68. doi: $10.3917 /$ pro323.0061

15. Gori, R. (2009). L'art des douces servitudes. Adolescence, 68 (2), 271-295. doi: 10.3917/ ado.068.0271

16. Gori, R. y Del Volgo, M.-J. (2009). L'idéologie de l'évaluation : un nouveau dispositif de servitude volontaire ? Nouvelle revue de psychosociologie, 8 (2), 11-26. doi: 10.3917/ nrp.008.0011

17. Jiambalvo, J. (2020). Managerial Accounting. New Jersey: Wiley.

18. Kaës, R., Correale, A., Diet, E., Duez, B., Kernberg, O., y Pinel, J.P. (1998). Sufrimiento y psicopatología de los vínculos institucionales. Elementos de la práctica psicoanalítica en institución. Buenos Aires: Paidós.

19. Linhart, D. (2013). Idéologies et pratiques managériales : du taylorisme à la précarisation subjective des salariés. Revista Sociedade e Estado, 28 (3), 519-539. Recuperado el 21/04/2017 de: http://www.scielo.br/pdf/se/v28n3/a04v28n3.pdf

20. Lordon, F. (2010). Capitalisme, désir et servitude. Marx et Spinoza. París: La Fabrique.

21. Mills, C.W. (1966). Les cols blancs. Essai sur les classes moyennes américaines. París: Maspero. (1 ${ }^{\text {a. ed., }}$ 1951).

22. Nye, J. (1990). Soft Power. Foreign Policy, 80 (Autumn), 153-171. URL: http://www.jstor. org/stable/1148580

23. Nye, J. (2004). El poder blando y la lucha contra el terrorismo. El Pais.es. Opinión (28-04-2004). Recuperado el 21/02/2020 de: https://elpais.com/diario/2004/04/28/ opinion/1083103206_850215.html

24. Orwell, G. (1977). 1984. París: Gallimard. Trad. Fr. A. Audiberti. (1a. ed., 1949).

25. Orwell, G. (1983). Un peu d'air frais. (1a. ed., 1939) Trad. Fr. R. Prêtre. París: Champ libre. 


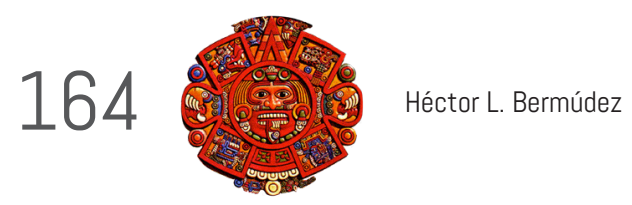

26. Pagès, M.; Bonetti, M.; Gaulejac, V. de; Descendre, D. (2019). L'emprise de l'organisation. Bruselas: Editions de I'Université de Bruxelles.

27. Rappin, B. (2019). De la révolution managériale au management révolutionnaire. Le Philosophoire, 51 (1), 187-202. https://www.cairn.info/revue-le-philosophoire-20191-page-187.htm

28. Rastier, F. (2013). Apprendre pour transmettre. L'éducation contre l'idéologie managériale. París: Presses Universitaires de France.

29. Rothmayr, C. (2013). Le droit et l'administration de la justice face aux instruments managériaux. Présentation du dossier, Droit et société, 84 (2), 275-289. URL: http:// www.cairn.info/revue-droit-et-societe-2013-2-page-275.htm

30. Rourke, F. E., \& Brooks, G. E. (1964). The "Managerial Revolution" in Higher Education. Administrative Science Quarterly, 9 (2), 154. doi:10.2307/2391232

31. Rumelt, R., Schendel, D. \& Teece, D. (1994). Fundamental Issues Strategy. In: R. Rumelt, D. Schendel \& D. Teece (ed.), Fundamental Issues in Strategy: A Research Agenda (947). Boston: Harvard Business School Press.

32. Saint-Martin, D. (2009). La régulation de l'éthique parlementaire: I'institutionnalisation d'un champ d'expertise contesté. Cahiers internationaux de sociologie, 126 (1), 21-37. doi: $10.3917 /$ cis.126.0021

33. Silverstein, B. (2020). Managerial Opportunism and Corporate Investment Efficiency (January 13, 2020). Available at SSRN: https://ssrn.com/abstract=3463419 or http:// dx.doi.org/10.2139/ssrn.3463419

34. Soulié, C. (2018). Idées d'universités et contre révolution managériale. Socio-logos, 13. http://journals.openedition.org/socio-logos/3235

35. Taylor, F. W. (1911). Shop Management. (1a. ed., 1903). New York and London: Harper \& Brothers Publishers.

36. Taylor, F. W. (1919). The Principles of Scientific Management. (1a . ed., 1911). New York and London: Harper \& Brothers Publishers.

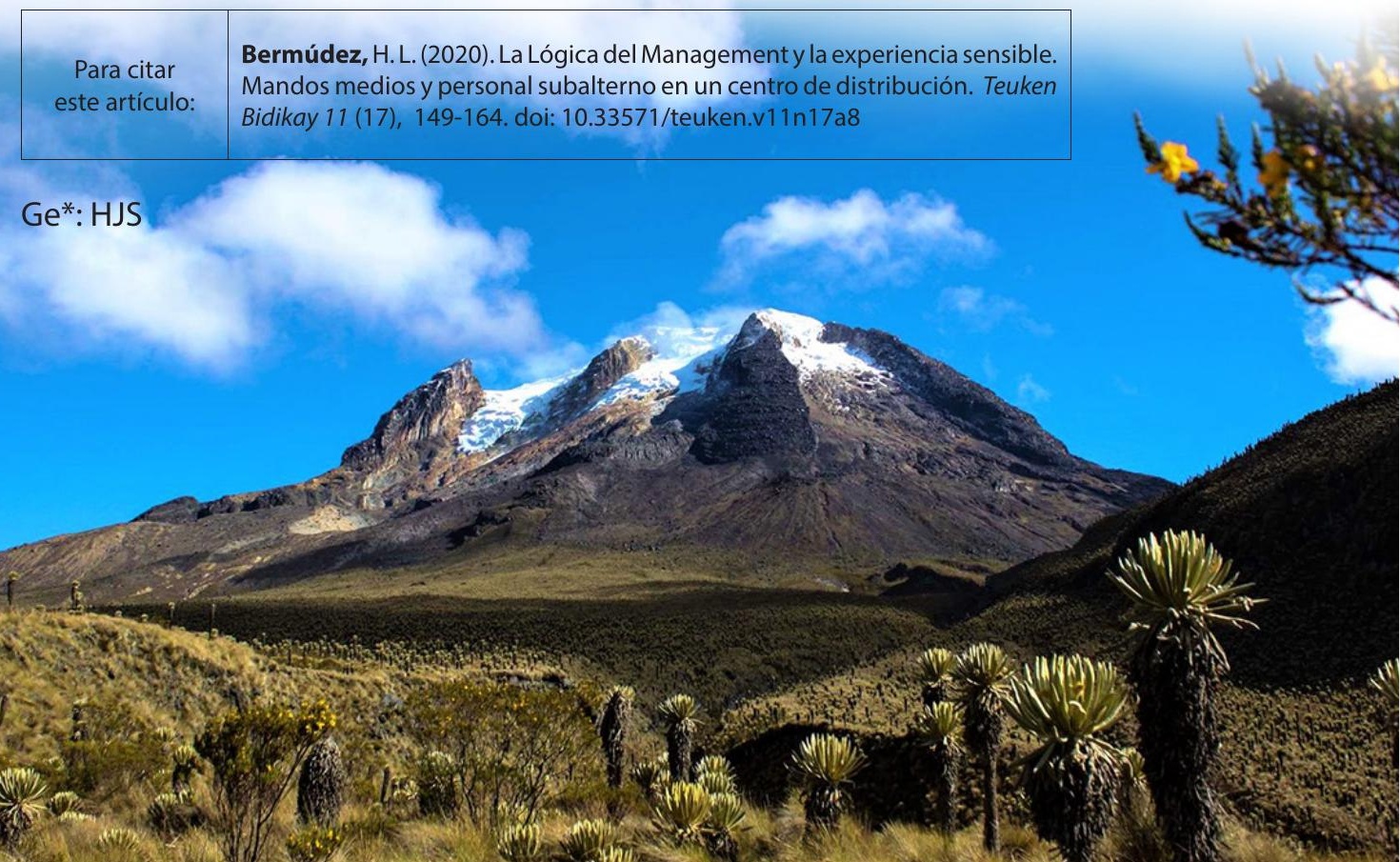

